Federal Reserve Bank of Minneapolis

Research Department Staff Report 302

March 2002

\title{
Is Lumpy Investment Relevant for the Business Cycle?
}

\author{
Julia K. Thomas* \\ University of Minnesota \\ and Federal Reserve Bank of Minneapolis
}

\begin{abstract}
Previous research has suggested that discrete and occasional plant-level capital adjustments have significant aggregate implications. In particular, it has been argued that changes in plants' willingness to invest in response to aggregate shocks can at times generate large movements in total investment demand. In this study, I re-assess these predictions in a general equilibrium environment. Specifically, assuming nonconvex costs of capital adjustment, I derive generalized (S,s) adjustment rules yielding lumpy plant-level investment within an otherwise standard equilibrium business cycle model. In contrast to previous partial equilibrium analyses, model results reveal that the aggregate effects of lumpy investment are negligible. In general equilibrium, households' preference for relatively smooth consumption profiles offsets changes in aggregate investment demand implied by the introduction of lumpy plant-level investment. As a result, adjustments in wages and interest rates yield quantity dynamics that are virtually indistinguishable from the standard model.
\end{abstract}

*Department of Economics, University of Minnesota, 1035 Heller Hall, 271 - 19th Avenue South, Minneapolis, MN 55455; jkt@econ.umn.edu. I thank John Cochrane, Aubhik Khan and Robert King for a series of discussions and suggestions that have substantially improved the quality of this work. I am also grateful to an anonymous referee, Marianne Baxter, Robert Chirinko, Andrew John, Patrick Kehoe, Timothy Kehoe, John Leahy, Edward Prescott and Stanley Zin, as well as seminar participants at the Board of Governors, Boston College, Calgary, Carnegie Mellon, the Federal Reserve Bank of Philadelphia, GSB-Chicago, Houston, Minnesota, Virginia, Wharton, the February 1999 NBER Economic Fluctuations and Growth meetings, and the 1999 Midwest Macroeconomics, Society for Economic Dynamics and NBER Summer Institute meetings for helpful comments. Any remaining errors are my own. The views expressed herein are those of the authors and not necessarily those of the Federal Reserve Bank of Minneapolis or the Federal Reserve System. 


\section{Introduction}

Recent studies have stressed the importance of infrequent and large, or lumpy, establishment-level capital adjustments in explaining the dynamics of aggregate investment. This paper reevaluates these findings, extending the analysis to allow for equilibrium prices. Specifically, I embed a generalized (S,s) model of establishmentlevel investment within an otherwise standard equilibrium business cycle model. Individual production units face random, nonconvex costs of undertaking capital adjustment and, as a result, invest only when there is sufficient distance between a target and their actual capital stocks. The extent of this tolerated capital imbalance varies across plants and evolves over time as a function of both aggregate and plant-level state variables. Thus the model delivers a time-varying distribution of establishments over capital levels.

The model is consistent with several empirical regularities arising from recent studies. First, establishment-level capital adjustment exhibits long episodes of relative inactivity punctuated by lumpy investments. For example, examining U.S. manufacturing plants in the Longitudinal Research Database, Doms and Dunne (1998) find that between 25 and 40 percent of the typical plant's total investment expenditure over a 17 year sample is concentrated into a single large episode. Furthermore, the probability of an investment spike rises in the level of capital imbalance. Again using the LRD, Caballero, Engel and Haltiwanger (1995) document an upward sloping empirical adjustment hazard, a finding confirmed by Caballero and Engel (1999) using aggregated data. Finally, this rising adjustment hazard is also evident in terms of time-since-adjustment. Cooper, Haltiwanger and Power (1999) link establishments' capital imbalances to the duration since their last large investment episode and find that the likelihood of an investment spike increases with the time since the last primary spike.

A general theme running through recent literature is that the micro-level quasifixity in capital has important implications for aggregate investment and, more generally, for aggregate economic activity. Doms and Dunne (1998) show that the number of plants experiencing their primary investment episode is strongly positively correlated with aggregate investment. Building on this evidence, other authors have emphasized how the interaction of upward sloping adjustment hazards with time- 
varying distributions of plant-level capital can produce large effects on aggregate investment demand, as certain histories of shocks lead plants to synchronize the timing of lumpy investment projects. Caballero, Engel and Haltiwanger (1995, page 3) suggest:

If the history of shocks and microeconomic actions is such that many production units are about to enter a feverish state of investment, then aggregate investment becomes very responsive to further shocks.

Caballero (1999, page 28) elaborates, providing the following example.

Suppose that a history of mostly positive aggregate shocks displaces the cross sectional distribution of imbalances toward the high part of the hazard. Such a sequence of events will not only lead to more investment along the path but also to more pent-up investment demand; indeed the cross sectional distribution [of capital imbalances] represents unfulfilled investment plans. But as unfulfilled demand "climbs" the hazard more units are involved in responding to new shocks; incremental investment demand is more easily boosted by further aggregate shocks, or depressed by a turnabout of events.

My model contains both elements emphasized above as central in determining the aggregate impact of nonconvex micro-level capital adjustment, namely rising adjustment hazards and time-varying plant distributions. However, its results contrast sharply with those of previous studies. In particular, when the business cycle is assumed to originate from exogenous changes in aggregate productivity, the statedependent adjustment economy exhibits a striking negative result: lumpy investment has only minor consequences for the reduced-form relations between productivity shocks and real aggregate quantities. Quantity dynamics are virtually identical to those generated by a standard equilibrium business cycle model characterized by frictionless investment. Given that establishments often have lengthy periods of investment inactivity, but are able to change the timing of their investment at relatively small cost, this similarity may seem surprising.

I trace the effective invariance of aggregate quantities to the influence of general equilibrium. The permanent income theory, embedded in the model, leads to consumption series that are highly similar across economies with and without costs of 
capital adjustment. In particular, households' preference for smooth consumption profiles restrains shifts in investment demand. This dampening force plays the predominant role in equilibrium investment determination and produces the invariance result.

The effect of equilibrium changes in relative prices upon aggregate investment demand is dramatic. Abstracting from such price adjustments, I find both quantitative and qualitative changes in the response of aggregate investment relative to the neoclassical benchmark. For example, following a persistent increase in productivity, an unusually large number of establishments synchronize the timing of their capital adjustment, and there is a strong shift in the cross-sectional distribution of plants across capital imbalances. This widespread reshuffling of investment timing causes the aggregate investment series to rise well above the level it would achieve were changes in adjustment rates suppressed. Further, it generates a series of oscillations that qualitatively distinguish the model's response. Thus, with prices held fixed, the model's predictions confirm earlier partial equilibrium findings. When markets clear, however, equilibrium price movements smooth the economy's response to such a degree that distributional effects are eliminated, and lumpy investment becomes largely unimportant to aggregate business cycle dynamics.

The organization of the remainder of the paper is as follows. Section 2 briefly reviews previous research related to the state-dependent lumpy investment model developed here. Sections 3 and 4 describe the economic environment, model solution and parameter choices. Section 5 presents the economy's dynamics relative to the frictionless neoclassical business cycle model and explains the similar results across economies. Section 6 concludes.

\section{Related Research}

Researchers have recently developed dynamic partial equilibrium models of discrete choice that achieve greater consistency with the micro-level evidence described above. Within these models, discrete investment choices are typically driven by the presence of nonconvexities, and $(\mathrm{S}, \mathrm{s})$ policies characterize investment. (Examples of (S,s) investment models include Abel and Eberly (1996), Bertola and Caballero (1994), Caballero and Engel (1991) and Caballero and Leahy (1996).) Plants exhibit 
nonlinear responses to shocks, as periods of inactivity are occasionally broken by lumpy investments when capital's deviation from its target exceeds a tolerance level. Abstracting from equilibrium interest and wage rate changes, such nonlinearities represent a marked departure both from the linear adjustment rules predicted by the traditional partial adjustment model, which assumes convex adjustment costs, and from the immediate convergence predicted in the absence of adjustment costs.

Caballero and Engel (1999) extend the (S,s) framework, developing a generalized $(\mathrm{S}, \mathrm{s})$ adjustment model that allows for probabilistic bands of inactivity, so that the likelihood of a discrete adjustment rises in the deviation of a plant's state from its desired value, rather than jumping discontinuously from zero to one. They find that their state-dependent adjustment model significantly outperforms the partial adjustment model in explaining 2-digit U.S. manufacturing investment, and they attribute this to the model's ability to "generate brisker expansions than its linear counterparts." ${ }^{1}$ Related work by Caballero, Engel and Haltiwanger (1995) and Cooper, Haltiwanger and Power (1999) provides further evidence for the relative success of state-dependent $(\mathrm{S}, \mathrm{s})$ adjustment in explaining aggregate investment.

Despite these findings, extensions of state-dependent adjustment frameworks to general equilibrium have been limited, as it is difficult to determine equilibrium when the aggregate state involves a distribution of production units, a high-dimensional object. Thus, as noted by Caplin and Leahy (1997, page 601),

One of the most limiting aspects of these models is that they focus exclusively on the impact that microeconomic inertia has on aggregate dynamics. They ignore the feedback from aggregates onto individual behavior.

My results will show that these equilibrium feedbacks dominate the distributional effects emphasized by partial equilibrium analyses.

One notable exception in the $(\mathrm{S}, \mathrm{s})$ investment literature is the model of Veracierto (1998). ${ }^{2}$ Assuming that the resale price of investment goods is some constant fraction of the purchase price, Veracierto embeds the costly reversibility model of Abel

\footnotetext{
${ }^{1}$ See Chirinko (1993) and Hassett and Hubbard (1996) for excellent surveys of the mixed empirical success of the partial adjustment model in explaining aggregate investment.

${ }^{2}$ Aside from investment theory, other leading examples of equilibrium $(\mathrm{S}, \mathrm{s})$ models include the price-setting models of Caplin and Leahy (1997) and Dotsey, King and Wolman (1999) and the inventory model of Fisher and Hornstein (2000).
} 
and Eberly (1996) within an equilibrium business cycle model. In the absence of a microeconomic estimate of the extent of investment irreversibility, he calibrates his model across a wide range of values and concludes that there are no quantitatively significant effects of such investment frictions for business cycle dynamics.

As explained by Caballero (1999), the irreversible investment model is designed to explain nonlinearities in the response of investment demand to Tobin's q. It cannot address the lumpy micro-level capital adjustment described above, since it tends to generate infrequent, but not lumpy, investment. In contrast, my model abstracts from irreversibilities and is calibrated using data on establishment-level lumpy investment. Given the emphasis across the partial equilibrium studies surveyed above, this choice is motivated by the belief that there is an important need to evaluate a general equilibrium model consistent with the lumpy investment and rising adjustment hazards found in micro-level data.

\section{Model}

I model state-dependent investment at the plant level using a generalized $(\mathrm{S}, \mathrm{s})$ framework. The approach is related to Caballero and Engel's (1999) generalized $(\mathrm{S}, \mathrm{s})$ model in its use of stochastic adjustment costs to simultaneously yield lumpy plant-level investment and smooth aggregates. Unlike traditional (S,s) models which assume nonstochastic costs, this allows for probabilistic adjustment thresholds that can capture the rising hazards observed in microeconomic data. The version herein yields straightforward aggregation and thus convenient extension to general equilibrium.

The economy is populated by a unit measure of production units differentiated by their stocks of capital. To isolate the effects of lumpy investment, I ensure equivalence along all other margins to a neoclassical benchmark model, discussed below, by abstracting from the entry or exit of establishments. This also facilitates the model's calibration, as empirical studies of establishment-level investment generally focus on continuing establishments (Doms and Dunne (1998)). Each establishment's production technology is characterized by diminishing returns with respect to variable inputs in production. ${ }^{3}$ Plants produce using capital and labor as variable inputs;

\footnotetext{
${ }^{3}$ This implicit assumption of a fixed factor determines plant size.
} 
they may frictionlessly adjust labor usage, but they face fixed labor costs of adjusting capital stock. These adjustment costs, denoted $\xi$, are independently and identically distributed across establishments and across time with a known cumulative distribution $G(\xi)$ and finite upper support $B$. Their denomination in labor units ensures that plants cannot effectively outgrow adjustment costs along the balanced growth path. Capital depreciates at rate $\delta$.

Associate a production unit that last acquired new capital $j$ periods in the past with the subscript $j$. Plant-level output is given by the Cobb-Douglas production function:

$$
y_{j t}=A_{t} k_{j t}^{\gamma} n_{j t}^{\nu}
$$

No plant can alter its current capital stock; a plant that last invested $j+1$ periods ago produces using its predetermined capital stock $k_{j t}$ and employment $n_{j t}$. Current productivity $A_{t}$, common to all establishments, is determined by the realization of a stochastic component, $z_{t}$, and a trend component, $X_{t}$. The $X_{t}$ component evolves deterministically with growth rate $\Theta_{A}$, while $z_{t}$ follows a mean zero $\operatorname{AR}(1)$ process in logs.

$$
\begin{gathered}
A_{t}=X_{t} z_{t} \\
z_{t}=z_{t-1}^{\rho} e^{\varepsilon_{t}}, \quad \varepsilon_{t} \sim N\left(0, \sigma_{\varepsilon}^{2}\right)
\end{gathered}
$$

After observing the current aggregate state and its individual adjustment cost, each plant chooses whether to undertake an investment action. If an establishment decides to adjust its capital for date $t+1$ production, it pays its current cost draw, $\xi w_{t}$ in units of output (where $w_{t}$ represents the real wage at date $t$ ) and chooses an appropriate investment to reach its desired capital stock. ${ }^{4}$

$$
k_{0, t+1}=(1-\delta) k_{j t}+i_{j t}
$$

In the absence of adjustment, the plant's capital stock at $t+1$ is that which remains after date $t$ production.

$$
k_{j+1, t+1}=(1-\delta) k_{j t}
$$

\footnotetext{
${ }^{4}$ Here, and in subsequent equations, commas distinguish subscripts only when necessary for clarity.
} 
Each plant's current flow profit is determined by its output less wage payments, investment and adjustment costs; these flow profits are returned in lump-sum fashion to households.

A representative household owns the portfolio of plants in the economy and supplies labor. The household values consumption and leisure in each period, with momentary utility given by $u\left(c_{t}, L_{t}\right)$, and discounts future utility by the factor $\beta$. It is endowed with one unit of time per period, which may be split between leisure $L_{t}$ and market activities $N_{t}$. Finally, current consumption is financed with income received from the economy's plants in the form of wages and profits.

Before I proceed further in the discussion of equilibrium and model solution, it is useful to aggregate the actions of the diverse population of plants described above. Note that all establishments share the same production technology and face the same distribution of adjustment costs. This implies that, irrespective of their current capital levels, all investing plants share the same expected stream of future marginal revenues for any given choice of future capital. Thus investors choose a common target capital $k_{0, t+1}$, and all plants adjusting at a given time are for practical purposes identical immediately following investment. The cross-sectional distribution of establishments over capital levels is therefore summarized by the distribution of plants across time-since-adjustment groups or, loosely, vintages, where each member of a group shares the same time since last capital adjustment and is thus associated with the same capital stock.

Next, given the large number of establishments present, each group contains a marginal plant whose cost draw makes it just worthwhile to invest. All plants of the same vintage drawing costs at or below this group-specific threshold cost also invest, implying that the investing fraction of any group, $\alpha_{j t}$, is retrievable from the adjustment cost CDF. Thus the nonconvex behavior of individual production units is conveniently represented by the fractions of plants in each group that undertake capital adjustment and the target capital stock of such plants.

At each date, the distribution of the economy's establishments across groups is summarized by two vectors. First, $\mathbf{k}_{t}=\left\{k_{j t}\right\}$, the vector of capital levels across time since adjustment groups, captures the support of the distribution. Next, the fraction of plants associated with each capital level is given by the predetermined vector $\boldsymbol{\Theta}_{t}=\left\{\theta_{j t}\right\}$, where each $\theta_{j t}$ describes the number of plants currently owning vintage 
$j$ capital stock, and $\theta_{0 t}$ denotes the number of plants that adjusted capital after production in the previous period. The evolution of the cross-sectional distribution over time is determined as follows. The support at time $t+1$ is determined through (4) and adjusting plants' common choice of $k_{0, t+1}$. Next, let $\boldsymbol{\alpha}_{t}=\left\{\alpha_{j t}\right\}$ denote the vector of adjustment rates. The fraction of plants associated with each point in the support at $t+1, \boldsymbol{\Theta}_{t+1}$, is summarized by equations (5) and (6) below and illustrated in figure 1.

$$
\begin{aligned}
\theta_{0, t+1} & =\sum_{j=0}^{\infty} \alpha_{j t} \theta_{j t} \\
\theta_{j, t+1} & =\theta_{j-1, t}\left(1-\alpha_{j-1, t}\right), \quad j=1,2, \ldots
\end{aligned}
$$

Membership in time-since-adjustment group 0 at date $t+1$ is determined by the fraction of all plants investing at date $t$, the population-weighted sum of adjustment fractions from each group. Membership in the remaining groups is governed by nonadjustment fractions; plants of each vintage $j$ that do not adjust at date $t$ become vintage $j+1$ plants in the subsequent period.

In addition to the evolution of the plant distribution, the economy is subject to a series of aggregate constraints. Household consumption cannot exceed aggregate production net of the investments made by all adjusting plants,

$$
c_{t} \leq \sum_{j=0}^{\infty} \theta_{j t} y_{j t}-\sum_{j=0}^{\infty} \theta_{j t} \alpha_{j t} i_{j t} .
$$

Hours worked by the household must satisfy the weighted sum of employment in production and adjustment activities across groups,

$$
\sum_{j=0}^{\infty} \theta_{j t} n_{j t}+\sum_{j=0}^{\infty} \theta_{j t} \Xi\left(\alpha_{j t}\right) \leq N_{t},
$$

where $\Xi\left(\alpha_{j t}\right)$ is the average adjustment cost paid from each group, conditional on the fraction of plants investing.

$$
\Xi\left(\alpha_{j t}\right) \equiv \int_{0}^{G^{-1}\left(\alpha_{j t}\right)} x d G(x)
$$

Competitive equilibrium allocations are determined through the solution of a planning problem. Specifically, the equilibrium allocation for the economy solves the following Bellman equation, 


$$
\begin{aligned}
V\left(\mathbf{k}_{t}, \boldsymbol{\Theta}_{t}, A_{t}\right)= & \max _{\left\{c_{t}, \mathbf{n}_{t}, N_{t}, \mathbf{i}_{t},\right.}\left[u\left(c_{t}, 1-N_{t}\right)+\beta E_{t} V\left(\mathbf{k}_{t+1}, \boldsymbol{\Theta}_{t+1}, A_{t+1}\right)\right], \\
& \left.\boldsymbol{\alpha}_{t}, \boldsymbol{\Theta}_{t+1}, k_{0, t+1}\right\}
\end{aligned}
$$

where the optimization is subject to aggregate goods and labor constraints in (7) and (8) - (9), plant-level production (1), and the evolution of the distribution of capital (3) - (6). Expectations are rational and consistent with (2).

The solution to the planning problem satisfies a series of efficiency conditions. As is standard, consumption is chosen such that the marginal utility of consumption is equated to the shadow value of output (the multiplier on the goods constraint (7)) denoted $\lambda_{t}$, and total labor hours equate the marginal rate of substitution between leisure and consumption to $w_{t}$ (the multiplier on the time constraint (8)) which represents the real wage.

$$
\begin{aligned}
\lambda_{t} & =D_{1} u\left(c_{t}, 1-N_{t}\right) \\
w_{t} & =\frac{D_{2} u\left(c_{t}, 1-N_{t}\right)}{D_{1} u\left(c_{t}, 1-N_{t}\right)}
\end{aligned}
$$

Plant-level employments in production satisfy the familiar static condition for labor choice under Cobb-Douglas production.

$$
n_{j t}=\left[\frac{\nu A_{t} k_{j t}^{\gamma}}{w_{t}}\right]^{\frac{1}{1-\nu}}
$$

The remaining efficiency conditions describe optimal adjustment fractions and target capital choice. Note that the finite upper support for the cost CDF, combined with a constant rate of capital depreciation making investment increasingly valuable across vintages, implies that the economy's history is redundant beyond a finite number of lags. Once a plant's capital stock has sufficiently depreciated, the value of investing eventually offsets the highest possible fixed cost. Thus, the stationary distribution of plants is characterized by an endogenously chosen vintage $J$ by which full adjustment occurs: $\alpha_{J}=1$. For $j<J$, optimal adjustment fractions are interior solutions equating the anticipated value of adjusting one additional plant from group $j$ to the additional adjustment cost entailed, $w_{t} \cdot G^{-1}\left(\alpha_{j t}\right)$ in units of output, and investment required. That is, for $j=0, \ldots, J-1$, 


$$
w_{t} G^{-1}\left(\alpha_{j t}\right)+i_{j t}=v_{0 t}-v_{j+1, t},
$$

where $v_{0 t}$ is the multiplier associated with (5), and $v_{j t}, j=1,2, \ldots, J-1$, are the multipliers associated with (6), representing the expected discounted value at date $t$ of having an additional plant of vintage $j$ at the start of date $t+1$.

$$
\begin{aligned}
v_{j t}= & E_{t}\left[\frac { \beta \lambda _ { t + 1 } } { \lambda _ { t } } \left(y_{j, t+1}-w_{t+1} n_{j, t+1}-\alpha_{j, t+1} i_{j, t+1}\right.\right. \\
& \left.\left.+\alpha_{j, t+1} v_{0, t+1}+\left(1-\alpha_{j, t+1}\right) v_{j+1, t+1}-w_{t+1} \Xi\left(\alpha_{j, t+1}\right)\right)\right]
\end{aligned}
$$

Define $\varphi_{j, t+1+j} \equiv \prod_{i=0}^{j}\left(1-\alpha_{i, t+1+i}\right)$ as the date $t$ probability that an investing plant will make no further investments through date $t+1+j$, and hence enter date $t+2+j$ as a member of nonadjustment group $j+1$. This represents the probability that the date $t$ investment level will continue to affect profits in each future period through date $t+j+2$. The optimal adjustment level is the investment required to reach the target capital stock that satisfies (13) below, equating the marginal utility cost of foregone consumption to the expected discounted marginal utility payoff of an additional unit of future capital.

$$
\begin{aligned}
\lambda_{t}= & E_{t}\left[\beta \lambda_{t+1}\left(\frac{\partial y_{0, t+1}}{\partial k_{0, t+1}}+(1-\delta) \alpha_{0, t+1}\right)\right. \\
& +\beta^{2} \lambda_{t+2}(1-\delta) \varphi_{0, t+1}\left(\frac{\partial y_{1, t+2}}{\partial k_{1, t+2}}+(1-\delta) \alpha_{1, t+2}\right) \\
& +\cdots \\
& +\beta^{J} \lambda_{t+J}(1-\delta)^{J-1} \varphi_{J-2, t+J-1}\left(\frac{\partial y_{J-1, t+J}}{\partial k_{J-1, t+J}}+(1-\delta) \alpha_{J-1, t+J}\right) \\
& \left.+\beta^{J+1} \lambda_{t+J+1}(1-\delta)^{J} \varphi_{J-1, t+J}\left(\frac{\partial y_{J, t+J+1}}{\partial k_{J, t+J+1}}+(1-\delta)\right)\right]
\end{aligned}
$$

Because each $k_{j, t+1+j}=(1-\delta)^{j} k_{0, t+1}$, the payoff to additional capital involves a discounted sum of the marginal effects on future profits continuing into the future until capital is readjusted. Hence the choice of target capital is dependent on expectations about a potentially long stream of future wages, interest rates, productivity levels and adjustment rates. 


\section{Model Solution and Parameter Choices}

Quantitative evaluation of the economy's business cycle behavior requires numerical methods to solve the model. The first step in the algorithm is the computation of a steady state. This computation requires the specification of a functional form for utility. Following Hansen (1985) and Rogerson (1988), I assume indivisible labor. The representative household's momentary utility is $u(c, L)=\log c+\zeta L$.

Along the balanced growth path, the technological frontier grows at rate $\frac{A_{t+1}}{A_{t}} \equiv$ $\Theta_{A}$, and the stochastic component $z_{t}$ is at its mean. The economy is detrended, and time series are expressed in terms of their trend deflated counterparts. After elimination of variables through substitution, the steady state is described by a system of $J+2$ simultaneous nonlinear equations in $\left(k_{0}, w,\left[\alpha_{0}, \cdots, \alpha_{J-1}\right]\right)$. I solve this nonlinear system using a quasi-Newton algorithm. Since $J$ itself is determined in the solution, the procedure iterates over values of $J$. The steady state for the economy involves the lowest value for $J$ that generates $\alpha_{J}=1$.

The second step in solving the model involves a near-steady state log-linear approximation. The model is reformulated as a system of first-order linear difference equations, and standard linear systems methods are employed to solve the system. The solution expresses each nonpredetermined endogenous variable as a linear function of the economy's state variables, and dynamic multipliers are retrieved using the King and Watson (1997) algorithm. The accuracy of the local approximation relies on the assumption that productivity shocks are sufficiently small that $J$ does not leave its long run value. To establish the validity of this local approximation, I have examined a large number of simulations of length 1000 periods (driven by the productivity process in (2) under the calibration below); in no case did equilibrium $\alpha_{j}, j=1, \ldots, J-1$, or $\theta_{j}, j=1, \ldots, J$, reach 0 or 1 boundaries.

I study the impact of lumpy establishment-level investment on the aggregate business cycle by contrasting the behavior of the above state-dependent adjustment economy to an otherwise identical economy characterized by frictionless investment. Plant-level production in this benchmark neoclassical economy takes the form described above, but there are no fixed costs on investment. As a result, plants are homogenous and have smooth decision rules governing their investment in every period. I discuss the parameter values which determine technology and preferences for 
both economies below.

The model's frequency, or length of a period, corresponds to one year. This choice is motivated by annual data on establishment level investment, which are used to parameterize the adjustment cost distribution. (I have also examined quarterly calibrations; the choice of frequency does not affect the nature of the results discussed below.) The parameter values for the benchmark economy are common choices in the quantitative stochastic dynamic general equilibrium literature and are taken to ensure the model's consistency with long-run values for key postwar U.S. aggregates. Specifically, the discount factor $\beta$ is taken to imply an average annual interest rate of 6.5 percent, given long-run per-capita output growth of 1.6 percent per year (King and Rebelo 1999). The rate of capital depreciation is selected to match a long-run investment-to-capital ratio of .076 (Cooley and Prescott 1995), and labor's share of output is .58, as consistent with direct U.S. estimates (King, Plosser and Rebelo 1988). Given these choices, capital's share is taken to yield an average capital-to-output ratio of 2.6 percent (Prescott 1986), and the parameter $\zeta$ governing the preference for leisure implies that, on average, 20 percent of available time is spent in market work (King, Plosser and Rebelo 1988). Finally, the exogenous stochastic process for productivity requires the choice of values for $\rho$, the first-order autocorrelation of $z_{t}$, and $\sigma_{\varepsilon}$, the standard deviation of the innovation term. I estimate these values from Solow residuals measured using Stock and Watson (1999) data on U.S. output, capital and total employment hours in 1953-1997.

Table 1 summarizes the parameterization for the benchmark model.

Table 1: Parameter choices

\begin{tabular}{||c|c|c|c|c|c|c|c||}
\hline \hline $\boldsymbol{\Theta}_{Y}$ & $\boldsymbol{\nu}$ & $\boldsymbol{\gamma}$ & $\boldsymbol{\delta}$ & $\boldsymbol{\zeta}$ & $\boldsymbol{\beta}$ & $\boldsymbol{\rho}$ & $\boldsymbol{\sigma}_{\varepsilon}$ \\
\hline 1.016 & .580 & .325 & .060 & 3.6142 & .954 & 0.9225 & 0.0134 \\
\hline \hline
\end{tabular}

The parameters of table 1 are also used for the state-dependent adjustment model, allowing close comparison with the benchmark. This is a consistent exercise, as aggregate quantities and prices across the two steady states are close. The remaining parameters are those involving the distribution of adjustment costs for the statedependent adjustment model. The cumulative density function for adjustment costs 
takes the general form,

$$
\begin{aligned}
G(\xi) & =\underline{\alpha}+a\left(\underline{z}-\frac{\xi}{B}\right)^{-\Psi} \\
\xi & \in[0, B]
\end{aligned}
$$

which, if not further restricted, adds 3 free parameters in the model. These are the upper support $B$, the parameter governing curvature $\Psi$ and $\underline{z}{ }^{5}$ For the results presented here, the form is restricted to imply a uniformly distributed cost, $(\Psi=-1$, leaving one cost parameter, the upper support, to be chosen. I examine more general cost distributions in an appendix to this paper.

The value of $B$ is selected using two key pieces of evidence on investment spikes noted by Doms and Dunne (1998): (i) In the average year, plants raising their real capital stocks by more than 30 percent (lumpy investors) comprise 25 percent of aggregate investment, and (ii) these investors constitute 8 percent of plants. Setting $B$ equal to 0.002 roughly matches these two observations. Lumpy investors constitute 6 percent of plants, and their investment activities account for 29 percent of aggregate investment. The chosen parameterization also implies that plants exhibiting annual capital growth below 10 percent make up 78 percent of all plants, which agrees well with the Doms and Dunne estimate of 80 percent.

\section{Results}

\subsection{Stationary State}

Table 2 displays the stationary state adjustment fractions and cross-sectional density of the plant distribution in the state dependent adjustment economy. Capital adjustment for any plant occurs within 5 years, and 29 percent of the economy's establishments invest in each period along the balanced growth path.

Table 2: The stationary plant distribution

\begin{tabular}{||rc|c|c|c|c|c||}
\hline \hline $\begin{array}{r}\text { time since adj. group } \mathbf{j}= \\
\begin{array}{r}\text { Adjustment fraction: } \alpha_{j} \\
\text { Population density: }\end{array}\end{array} \theta_{j}$ & 0.059 & 0.197 & 0.377 & 0.576 & 0.782 & 1.000 \\
\cline { 2 - 8 } & 0.293 & 0.276 & 0.221 & 0.138 & 0.059 & 0.013 \\
\hline \hline
\end{tabular}

\footnotetext{
${ }^{5}$ The remaining terms, $\underline{\alpha}$ and $a$, are determined by the restrictions $G(0)=0$ and $G(B)=1$.
} 
The most noteworthy feature of this table is that adjustment fractions steadily rise across time-since-adjustment groups. The value of adjustment increases as plant-level capital depreciates, while the fraction of establishments drawing costs at or below any particular level is constant over vintages. Thus the economy exhibits the increasing adjustment hazard discussed in section 1.

\subsection{Business Cycles}

In this section, I consider the dynamic behavior of the state dependent adjustment model versus the benchmark model. These models' distinct investment technologies suggest substantial differences should exist in their aggregate dynamics. Specifically, the state-dependent adjustment model includes the two elements emphasized by previous authors as important in explaining aggregate investment: heterogeneity of capital across plants and rising adjustment hazards. When productivity shocks change target capital, shifts in the adjustment hazard (across the plant distribution) may produce large changes in the number of current investors. The resulting shifts in subsequent distributions of plants drive additional fluctuations in aggregate investment. By contrast, the benchmark model has no such mechanism.

I also compare the state dependent adjustment model to a third, constant adjustment, model in which time variation in adjustment fractions is suppressed. There, the plant distribution and adjustment fractions across vintages are fixed at the stationary values of table 2 , and the fraction of plants adjusting is constant at 29 percent in every period. Through that model's inclusion, I gauge the importance of the interaction between increasing adjustment hazards and changes in the cross-sectional distribution of establishments. Specifically, a comparison of the constant and statedependent adjustment models addresses the following question: If adjustment rates are carefully chosen so that they match the optimal long-run hazard, how much is lost in terms of short-run dynamic performance when we assume them constant over the cycle? The results that follow indicate that the loss is minimal if one's interest is in aggregate quantities.

Two additional sets of results are provided for reference in the tables discussed below. First, population moments for a traditional model of staggered capital adjust- 
ment, the partial adjustment model, are included. This alternative model smooths aggregate investment demand through the inclusion of convex costs that induce plants to gradually adjust their capital stocks in response to shocks. ${ }^{6}$ (Table 3 briefly summarizes the models considered, along with their abbreviations in subsequent tables.) Second, I present corresponding moments for real per-capita GDP, consumption, investment, hours and real wage and interest rates (constructed from nominal interest rates on treasury bills, adjusted for expected inflation) in the U.S. during 1953-97. Each series, taken from the Stock and Watson (1999) data set, is annualized and HP-filtered for comparison with model results.

Table 3: Summary of models

\begin{tabular}{||c|l|l||}
\hline \hline B & Benchmark neoclassical & no adjustment costs \\
\hline SD & State-dependent adjustment & $\begin{array}{l}\text { nonconvex adjustment costs; } \\
\text { endogenously varying adjustment rates }\end{array}$ \\
\hline CA & Constant adjustment & $\begin{array}{l}\text { nonconvex adjustment costs; } \\
\text { adjustment rates fixed at table } 2 \text { values }\end{array}$ \\
\hline PA & Partial adjustment & convex adjustment costs \\
\hline \hline
\end{tabular}

\section{Quantities}

I begin with an examination of impulse responses across the benchmark, statedependent adjustment and constant adjustment models that are my primary focus. Figure 2 presents the first 10 periods of each economy's response to a persistent aggregate productivity shock driven by an initial rise of one percent. The figure reveals a surprising similarity in aggregate investment and employment behavior across the three models. The same observation holds for consumption and output series, as will be evident from the discussion below.

To further explore the apparent invariance of aggregate quantities to underlying investment timing, tables 4-7 present selected population moments implied by each

\footnotetext{
${ }^{6}$ Here, the convex function governing adjustment costs, $h\left(\frac{K_{t+1}-(1-\delta) K_{t}}{K_{t}}\right)$, is parameterized to yield a steady-state elasticity of the investment-to-capital ratio to Tobin's marginal $q$ of 5.98 , as in Kiyotaki and West (1996).
} 
model's dynamic multipliers. Casual inspection of these tables indicates that the benchmark business cycle model suffers a number of well-recognized difficulties in matching important features of U.S. business cycles. ${ }^{7}$ For the purposes of this study, however, what is perhaps more striking is that the inclusion of state-dependent lumpy investment patterns neither improves, nor even affects, model performance along any of these dimensions.

Table 4 reveals that the standard deviations for output, investment, employment and consumption are essentially identical for the benchmark and state-dependent adjustment economies. The similarities there extend to the constant adjustment model as well, which exhibits only somewhat reduced investment volatility. That closeness is further emphasized by contrast to the traditional partial adjustment model, which exhibits a substantially weakened cycle due to excessively smooth investment demand. The overall similarity across models is also seen in the first and second order autocorrelations of table 6 and in the contemporaneous and lagged correlations with output reported in tables 5 and 7 . Consistent with its slightly reduced relative investment volatility, autocorrelations for the constant adjustment model's output, investment and employment series are somewhat higher, as are its investment and employment correlations with output.

The discussion above raises two questions. First, given that adjustment fractions cannot respond to aggregate shocks in the constant adjustment model, why does it nonetheless achieve such similar results for aggregate investment (and hence other aggregate quantities) when compared to the state-dependent adjustment economy? Second, how can the presence of adjustment frictions that lead to lumpy plant-level investment have so little impact on aggregate dynamics; that is, why does the statedependent adjustment economy so strikingly resemble the benchmark? To resolve these questions, I next examine the differences across economies.

\section{Intensive versus extensive margin capital adjustment}

First, in comparing the constant and state-dependent adjustment results, note that aggregate capital stock can generally be increased via two channels: the number

\footnotetext{
${ }^{7}$ The model exhibits weak propagation of the cycle, excessive volatility in investment and wages, and inadequate variability in consumption. Further, it fails to generate realistic interest rate dynamics, producing neither sufficient variability nor the strong negative correlation with output found in the data. See King and Rebelo (1999) for a more complete discussion.
} 
of adjusting plants and the target capital chosen by such plants. In figure 3 , the number of investing plants rises with the productivity shock in the state-dependent adjustment economy. By construction, the number of investors does not vary in the constant adjustment economy; however, there, in contrast to the smooth and gradual adjustment in the state-dependent model, target capital for adjustors rises steeply in response to the productivity shock. Heightened precautionary investment arises because high productivity is expected to persist, but it may be some time before a current investor will be able to reinvest. This important difference in individual investment levels is the primary factor driving the models' closeness in aggregate investment for two reasons. First, the trade-off between the number of adjusting establishments and the target capital to which they adjust is quite effective despite the departure from constant returns at plant-level. Moreover, the fixed adjustment hazard in the constant adjustment model is not particularly restrictive, as the statedependent model exhibits relatively small changes in the number of adjusting plants. I return to this unexpected lack of distributional effects below.

\section{$\underline{\text { Prices }}$}

For each model, indivisible labor implies that the real wage is proportional to consumption. Figure 4a reveals that wage (and consumption) responses are essentially identical across models. There are more pronounced differences in interest rates, as seen in figure $4 \mathrm{~b}$, particularly when the constant adjustment model is compared to the benchmark or state-dependent adjustment model. Turning to table 4, note that, while relative investment volatility differs by less than one-tenth of one percent between the benchmark and state-dependent adjustment economies, the benchmark interest rate is about 1.4 percent more variable than in the state-dependent adjustment economy. Comparing the benchmark to the constant adjustment model, this interest rate gap is much larger, at sixteen percent, while there is only a two percent difference in investment volatility. Similarly, in tables $5-7$, the sharpest difference across models occurs with respect to the interest rate. These distinctions suggest that the similarities in aggregate quantities across models share in large part a single explanation, intertemporal price movements.

Consider the following. Thusfar, I have focused primarily upon the sharp differences in factor demands that arise from nonconvexities in the adjustment cost 
structure. Taken alone, this should necessarily imply significant differences in aggregate behavior across economies. Common across economies, factor supplies (savings and work effort) are derived from ex-ante identical representative households. Hence, the close dynamical behavior of aggregate quantities indicates a critical role for factor supply. Equivalently, it suggests the predominant importance of equilibrium.

If the primary mechanism generating similar responses across economies does so through equilibrium price movements, then model behavior should become distinct when price dynamics are removed. Figure 5 presents model responses to the persistent shock described above, this time with wage and interest rate changes suppressed. Without the smoothing effect of price changes, the response in the benchmark model is large and immediate, while the constant adjustment model exhibits a much smaller and more gradual response, due to plants' inability to change the timing of investment. By contrast, higher establishment-level productivity sharply raises both the size of investments and the number of investors in the state-dependent adjustment model, and its response is pushed substantially above the constant adjustment case. Further, the model now exhibits oscillations, a consequence of a high initial rise in adjustment rates that echoes through subsequent distributions of plants.

Sharp divergence in aggregate response under fixed prices verifies the claim; the essential invariance in equilibrium quantity responses arises from households' preference for smooth consumption paths. Though the preference specification here implies a high elasticity of intertemporal substitution, at unity, households are nonetheless reluctant to accommodate large changes in investment demand. Despite the differences in factor demands, households in each of these economies are highly successful in smoothing changes in permanent income, and essentially achieve the same consumption profiles, when markets clear. The sharp rises in demand (figure 5) are largely offset, and the adjustment process slowed, through upward pressure on interest rates over those dates when there are tendencies for large capital adjustments. Interest rate rises are strongest in the benchmark economy, where investment demand is otherwise unrestrained, and mildest for the constant adjustment economy, where fixed adjustment rates dampen investment demand. It is worth noting that, while aggregate quantities remain similar across economies, differences in prices become more pronounced under alternative calibrations. Larger adjustment costs raise the gap in interest rate volatility between the benchmark and state-dependent adjustment 
economies. Additionally, stronger decreasing returns make the trade-off between intensive and extensive margin adjustment less effective, leaving interest rate volatility even more markedly reduced in the constant adjustment economy. ${ }^{8}$

I have shown that price movements smooth aggregate quantity responses in the frictionless benchmark model, yielding strong resemblance to economies where investment demand necessarily responds more gradually. These same equilibrium forces eliminate the state-dependent adjustment model's investment oscillations, dampening the distributional effects emphasized by previous research. In the absence of price movements, these distributional effects are strong, as seen in panel (a) of figure 6. There, with price changes suppressed, a one-percent rise in productivity nearly doubles the number of investors (members of group 0 ). In nearby dates, a large fraction of these extra plants do not adjust, reducing the number of current investors below trend and raising population in subsequent time-since-adjustment groups. As a result, investment demand falls below its average in figure 5, then returns to trend through a series of dampened oscillations as the plant distribution resettles. By contrast, panel (b) of figure 6 shows that changes in population densities across groups are minor with market-clearing price adjustment. Equilibrium restrains such changes in two ways. First, rises in the value of undertaking early investment are reduced by increases in the market-clearing interest rate, largely offsetting the tendency for many extra plants to invest. In addition, the opportunity cost of the adjustment activity rises with the procyclical real wage, further deterring early investments. As a result, productivity shocks produce very little disruption in the equilibrium distribution of plants across vintages, and the dynamics of aggregate investment are not qualitatively affected by the presence of heterogeneous plant-level capital adjustment.

\section{Concluding Remarks}

I have adapted the neoclassical business cycle model to allow for lumpy capital adjustments within individual establishments. My approach implements an aggregation that maps a large number of individual decisions into a small number of smooth behavioral restrictions that describe the economy. This allows the incorporation

\footnotetext{
${ }^{8} \mathrm{I}$ present results under these and other alternative parameterizations in an appendix available upon request.
} 
of nonconvexities at the plant level without sacrificing the tractability of standard methods for computing general equilibrium.

Previous partial equilibrium (S,s) models of lumpy adjustment have stressed important amplification and propagatory effects arising from flexibly timed discrete investment activities of heterogenous establishments. My model contains the essential ingredients required to produce these features. Specifically, when investment demand is unrestrained by changes in wages and interest rates, the model demonstrates its potential for large synchronizations in investment timing in response to aggregate shocks. As shown in figure 5, these large changes in investment timing can produce sufficiently large disturbances to the distribution of plants as to alter the path of aggregate investment demand both quantitatively and qualitatively relative to a business cycle model lacking establishment-level capital heterogeneity.

The importance of market-clearing price adjustment is vivid in the analysis. Were the method less tractable, so that the examination ended with a such a fixed price figure, one would be led to conclude that lumpy investment plays a substantial role in aggregate dynamics. In fact, in equilibrium, this is shown to be incorrect. Large distributional shifts disappear in the presence of relatively minor price changes, and the inclusion of lumpy plant-level investment does not significantly alter the equilibrium predictions of the traditional neoclassical equilibrium business cycle model.

This invariance of aggregate dynamics to the presence of lumpy capital adjustment at the micro-level is not special. Similar results arise under a variety of specifications for the underlying adjustment cost distribution, household preferences, as well as the relative importance of capital and labor inputs in production. Of course, some modifications to the current environment may allow lumpy investment a more prominent aggregate role. While I have confined this study to economies in which aggregate productivity shocks are the sole exogenous source of fluctuations, it is possible that disturbances exerting more direct effects on the plant distribution (for example changes in investment tax credits or depreciation allowances) may generate dynamic effects more consistent with the predictions of figure 5. Alternatively, given that the current finding rests largely on the importance of household preferences in determining equilibrium quantities, it is also possible that relaxing the assumptions of complete markets or perfect competition may sufficiently weaken the role of the representative household as to overturn the result. 


\section{References}

[1] Abel, Andrew B. and Janice C. Eberly [1996], "Optimal Investment with Costly Reversibility," Review of Economic Studies 63, 581-93.

[2] Bertola, Giuseppe and Ricardo J. Caballero [1994], "Irreversibility and Aggregate Investment," Review of Economic Studies 61, 223-246.

[3] Caballero, R. J. [1999], "Aggregate Investment," chapter 12 in M. Woodford and J. Taylor (eds.) Handbook of Macroeconomics IB Elsevier Science.

[4] Caballero, Ricardo J. and Eduardo M. R. A. Engel [1991], "Dynamic (S,s) Economies," Econometrica 59, 1659-1686.

[5] Caballero, Ricardo J. and Eduardo M. R. A. Engel [1999], "Explaining Investment Dynamics in U.S. Manufacturing: A Generalized (S, s) Approach," Econometrica 67, 783-826.

[6] Caballero, Ricardo J., Eduardo M. R. A. Engel and John C. Haltiwanger [1995], "PlantLevel Adjustment and Aggregate Investment Dynamics," Brookings Papers on Economic Activity 2, 1-54.

[7] Caballero, Ricardo J. and John V. Leahy [1996], "Fixed Costs: The Demise of Marginal q," NBER Working Paper No. 5508.

[8] Caplin, Andrew S. and John Leahy [1997], "Aggregation and Optimization with StateDependent Pricing," Econometrica 65, 601-625.

[9] Chirinko, Robert S. [1993], "Business Fixed Investment Spending: Modeling Strategies, Empirical Results, and Policy Implications," Journal of Economic Literature 31: 18751911.

[10] Cooley, Thomas F. and Edward. C. Prescott [1995], "Economic Growth and Business Cycles," chapter 1 in T. F. Cooley (ed.) Frontiers of Business Cycle Research Princeton University Press.

[11] Cooper, Russell W., John C. Haltiwanger and Laura Power [1999], "Machine Replacement and the Business Cycle: Lumps and Bumps," American Economic Review 89, 921-946.

[12] Doms, Mark and Timothy Dunne [1998], "Capital Adjustment Patterns in Manufacturing Plants," Review of Economic Dynamics 1, 409-430.

[13] Dotsey, Michael, Robert G. King and Alexander L. Wolman [1999], "State Dependent Pricing and the General Equilibrium Dynamics of Money and Output," Quarterly Journal of Economics 114, 655-90.

[14] Fisher, Jonas D. M. and Andreas Hornstein [2000], "(S,s) Inventory Policies in General Equilibrium," Review of Economic Studies 67, 117-45.

[15] Hansen, Gary D. [1985], "Indivisible Labor and the Business Cycle," Journal of Monetary Economics 16, 309-327.

[16] Hassett, Kevin A. and R. Glenn Hubbard [1996], "Tax Policy and Investment," NBER Working Paper 5683. 
[17] King, Robert G., Charles I. Plosser and Sergio T. Rebelo [1988], "Production, Growth and Business Cycles: I. The Basic Neoclassical Model," Journal of Monetary Economics $21,195-232$.

[18] King, Robert G. and Sergio T. Rebelo [1999], "Resuscitating Real Business Cycles," chapter 14 in M. Woodford and J. Taylor (eds.) Handbook of Macroeconomics IB Elsevier Science.

[19] King, Robert G. and Mark W. Watson [1997], "The Solution of Singular Linear Difference Systems Under Rational Expectations," working paper.

[20] Kiyotaki, Nobuhiro and Kenneth D. West [1996], "Business Fixed Investment and the Recent Business Cycle in Japan," in B. S. Bernanke and J. J. Rotemberg (eds.) NBER Macroeconomics Annual 1996, 277-323.

[21] Prescott, Edward C. [1986], "Theory Ahead of Business Cycle Measurement," Federal Reserve Bank of Minneapolis, Quarterly Review 10, 9-22.

[22] Rogerson, Richard [1988], "Indivisible Labor, Lotteries and Equilibrium," Journal of Monetary Economics 21, 3-16.

[23] Stock, James H. and Mark W. Watson [1999], "Business Cycle Fluctuations in U.S. Macroeconomic Time Series," chapter 1 in M. Woodford and J. Taylor (eds.) Handbook of Macroeconomics IA Elsevier Science.

[24] Veracierto, Marcelo [1998], "Plant Level Irreversible Investment and Equilibrium Business Cycles," Federal Reserve Bank of Chicago WP-98-1. 
Figure 1: Evolution of plant distribution

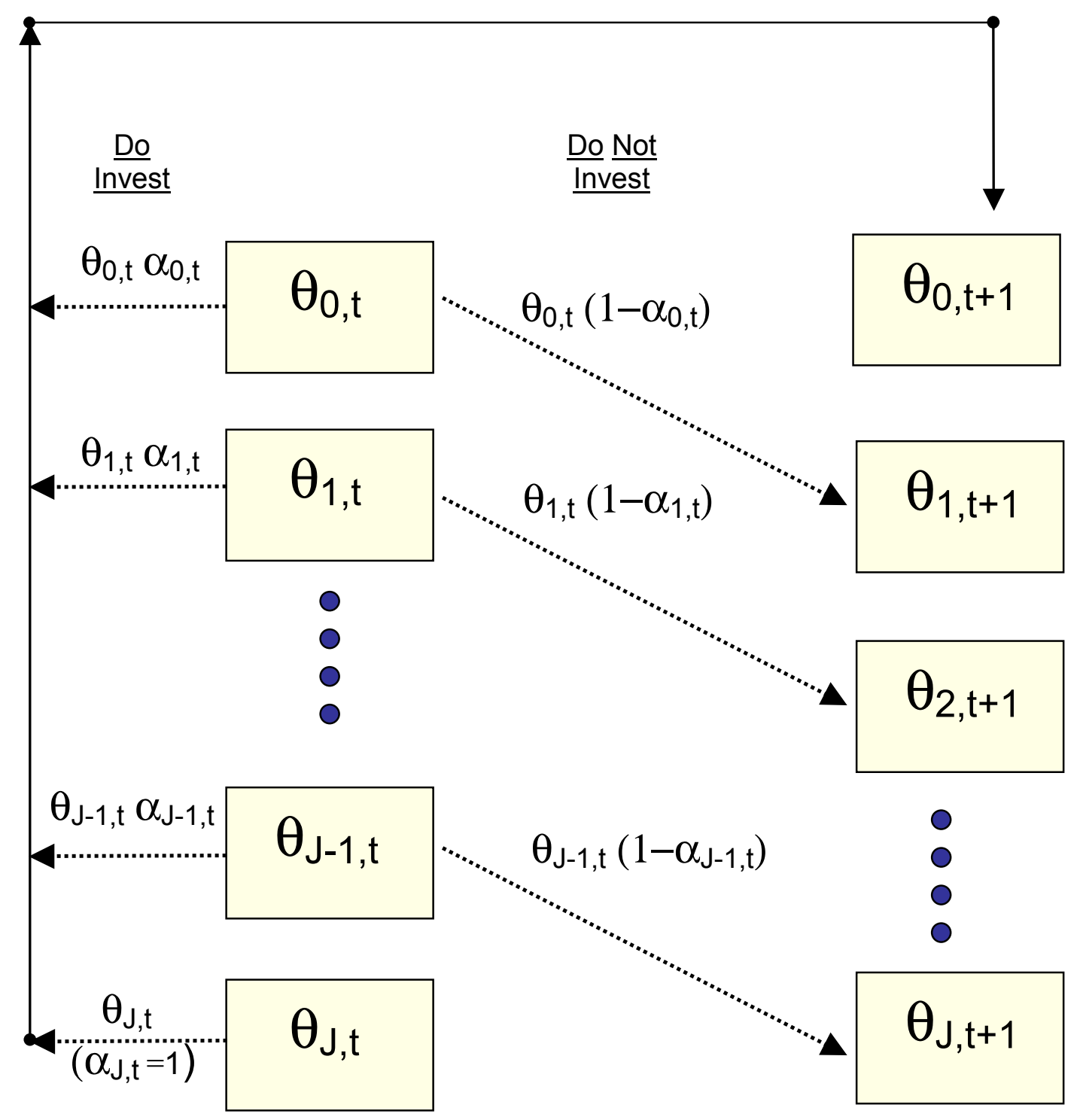

Membership in group 0 at date $\mathrm{t}+1$ (total investors at date $\mathrm{t}$ ): $\theta_{0, \mathrm{t}+1}=\Sigma \theta_{\mathrm{j}, \mathrm{t}} \alpha_{\mathrm{j}, \mathrm{t}}$. Membership in remaining groups $(\mathrm{j}=1,2, \ldots)$ at date $\mathrm{t}+1$ : $\theta_{\mathrm{j}, \mathrm{t}+1}=\theta_{\mathrm{j}-1, \mathrm{t}}\left(1-\alpha_{\mathrm{j}-1, \mathrm{t}}\right)$. 
Figure 2: Impulse responses for aggregate quantities

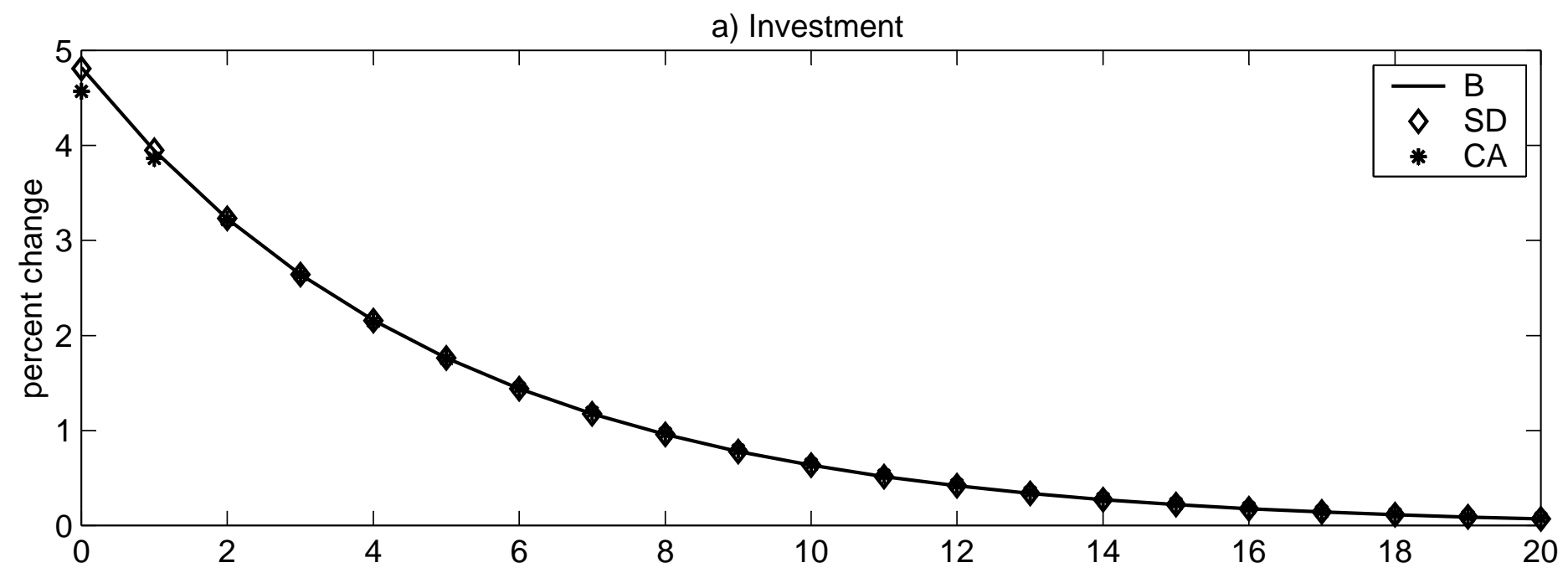

b) Employment

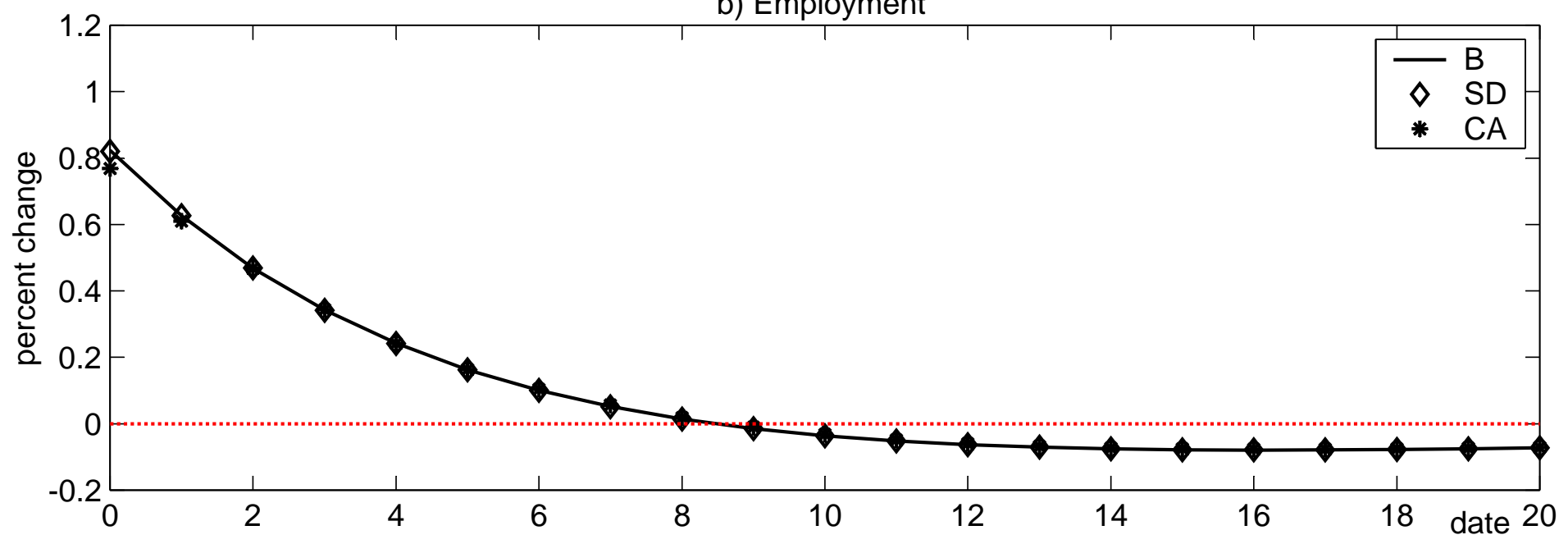

Percentage deviations from (growth-deflated) steady state in response to 1 percent rise in aggregate productivity. B: Benchmark; SD: State-dependent adjustment; CA: Constant adjustment. 
Figure 3: Impulse responses in extensive and intensive capital adjustment

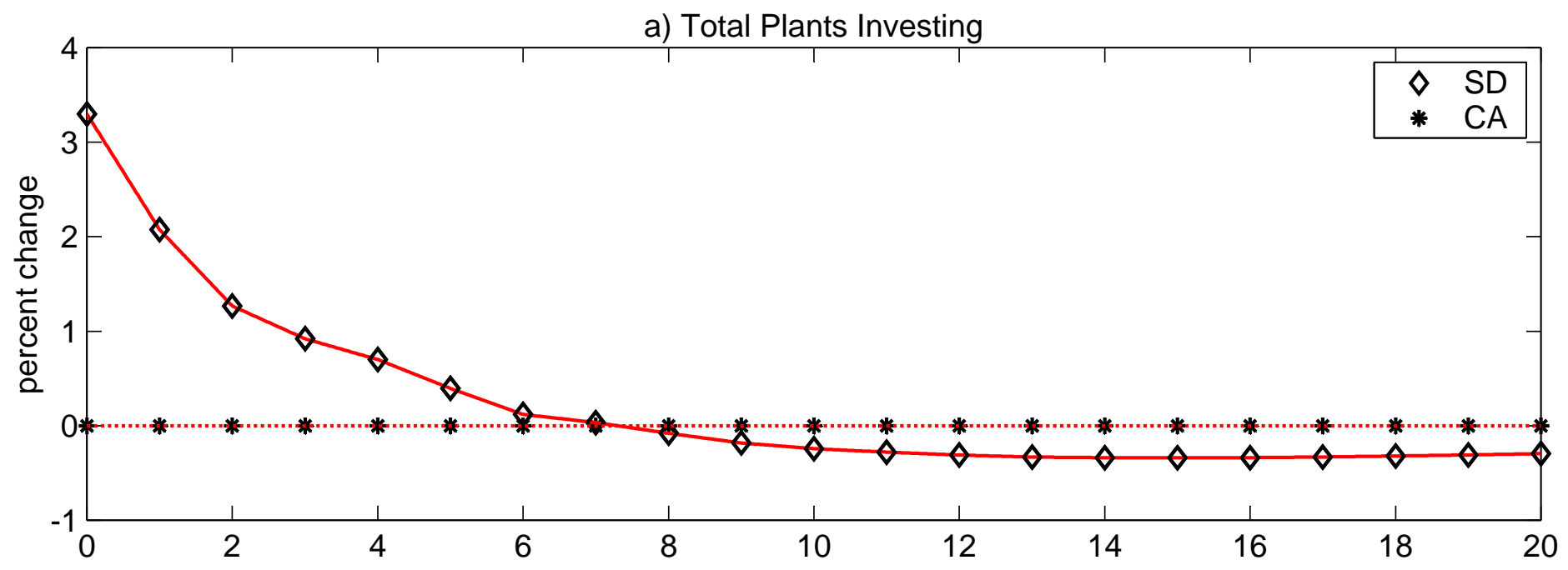

b) Target Capital

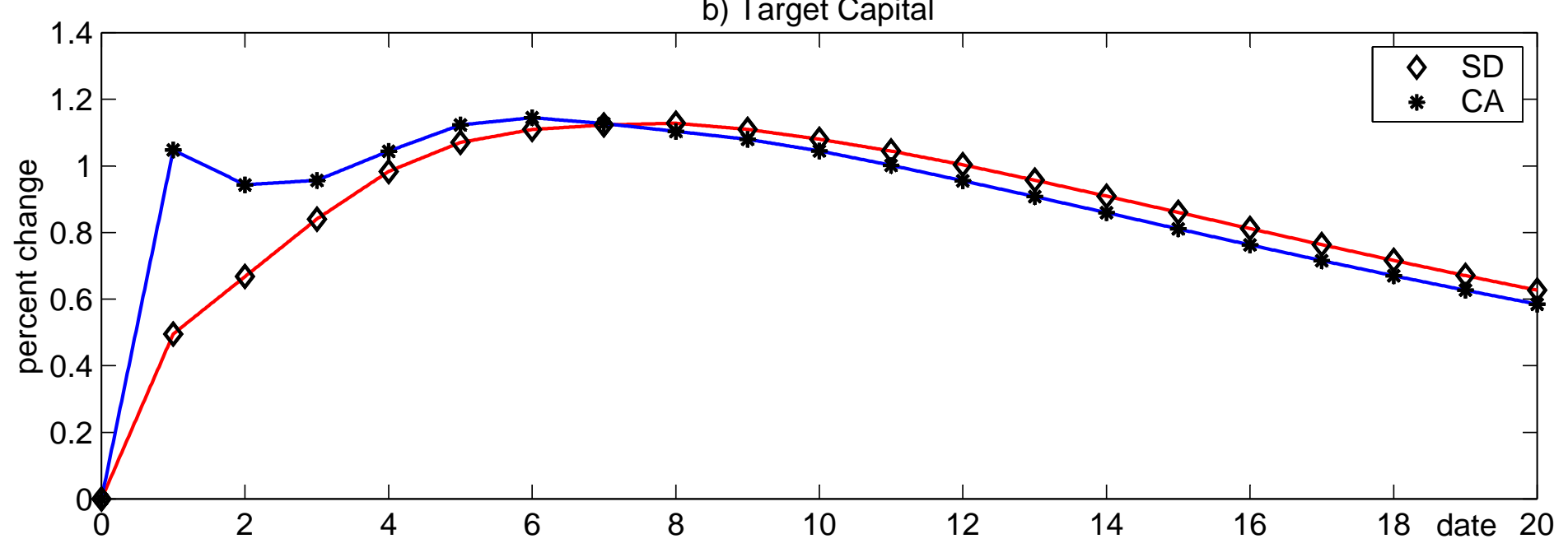

Percentage deviations from (growth-deflated) steady state in response to 1 percent rise in aggregate productivity. SD: State-dependent adjustment; CA: Constant adjustment. 
Figure 4: Impulse responses in prices

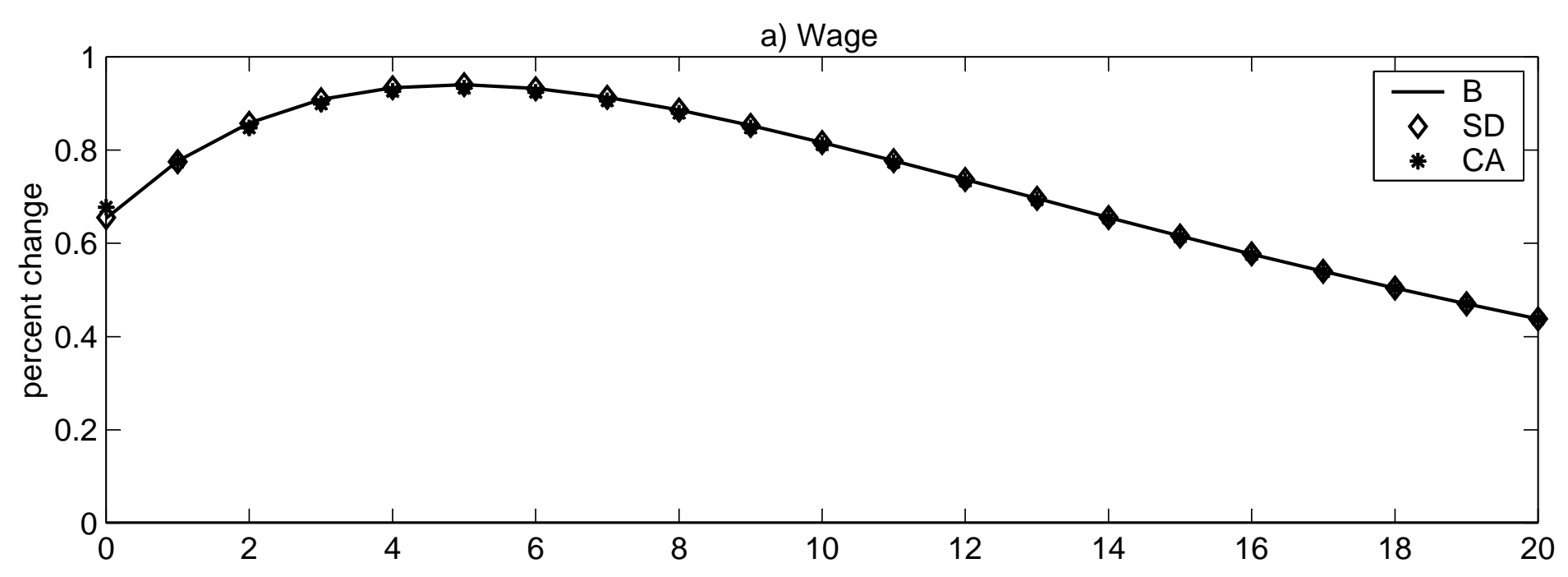

b) Interest Rate

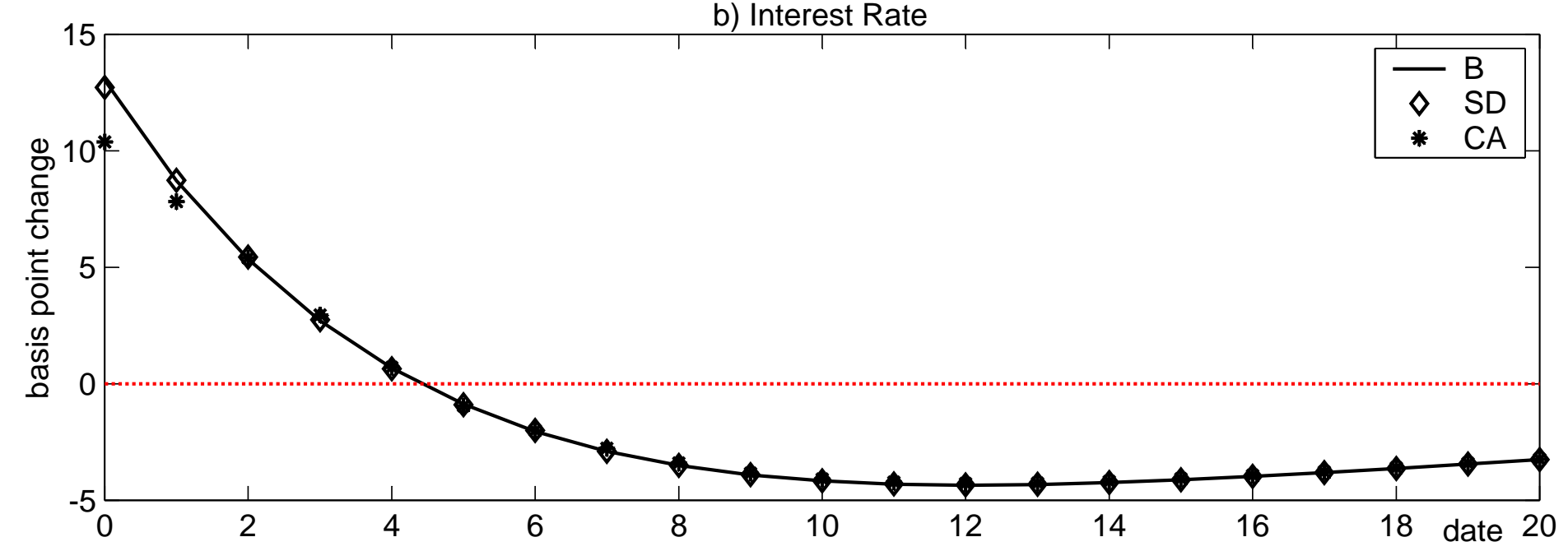

Percentage / basis point deviations from (growth-deflated) steady state in response to 1 percent rise in aggregate productivity. B: Benchmark; SD: State-dependent adjustment; CA: Constant adjustment. 
Figure 5: Aggregate quantity responses under fixed prices

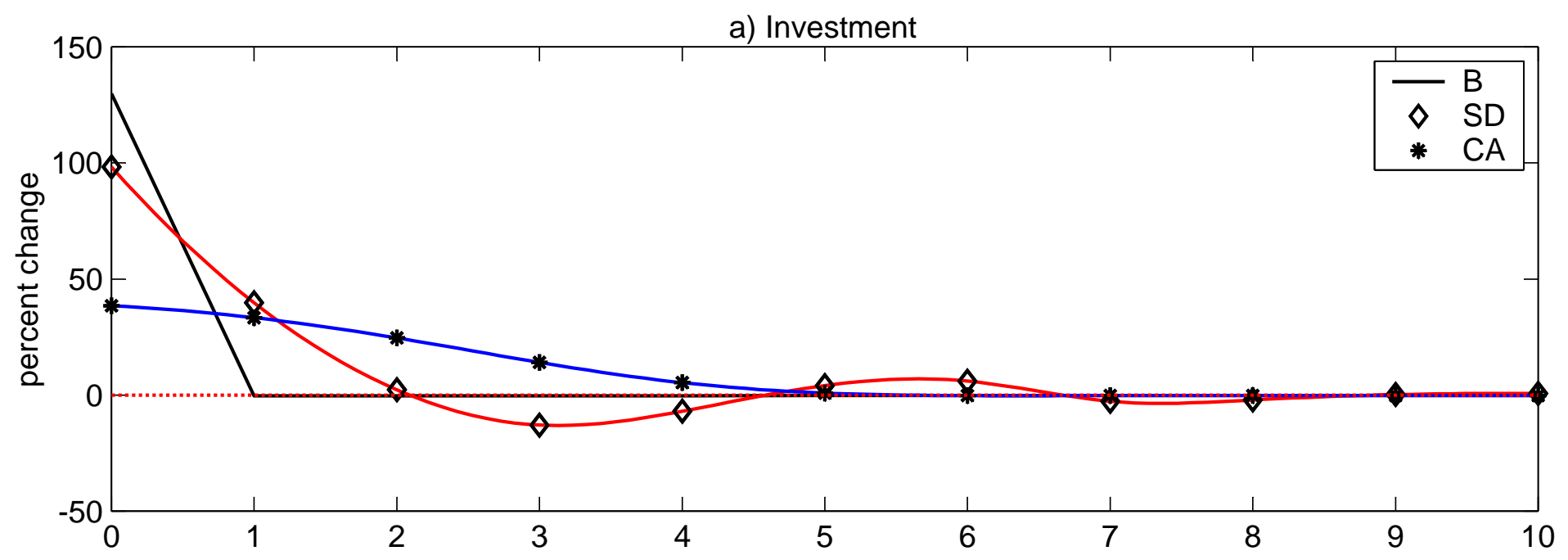

b) Employment

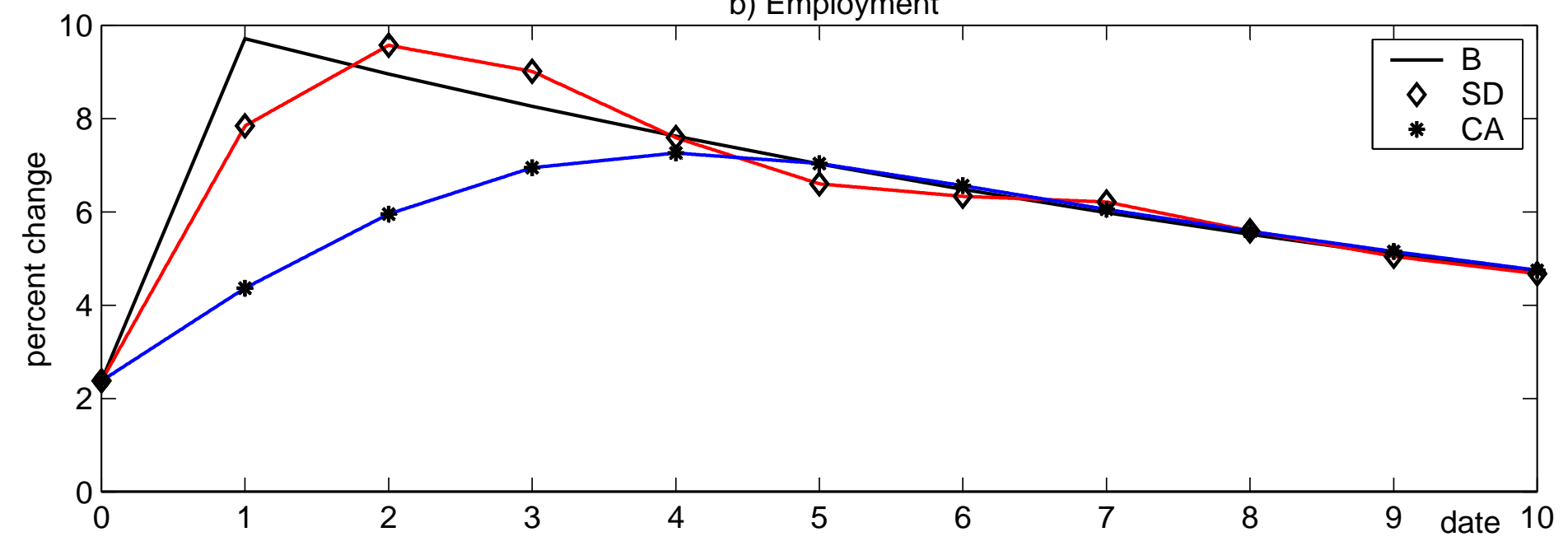

Percentage deviations from (growth-deflated) steady state with a 1 percent rise in aggregate productivity. Prices fixed at steady state. B: Benchmark; SD: State-dependent adjustment; CA: Constant-adjustment. 
Figure 6: Responses in state-dependent adjustment plant distribution
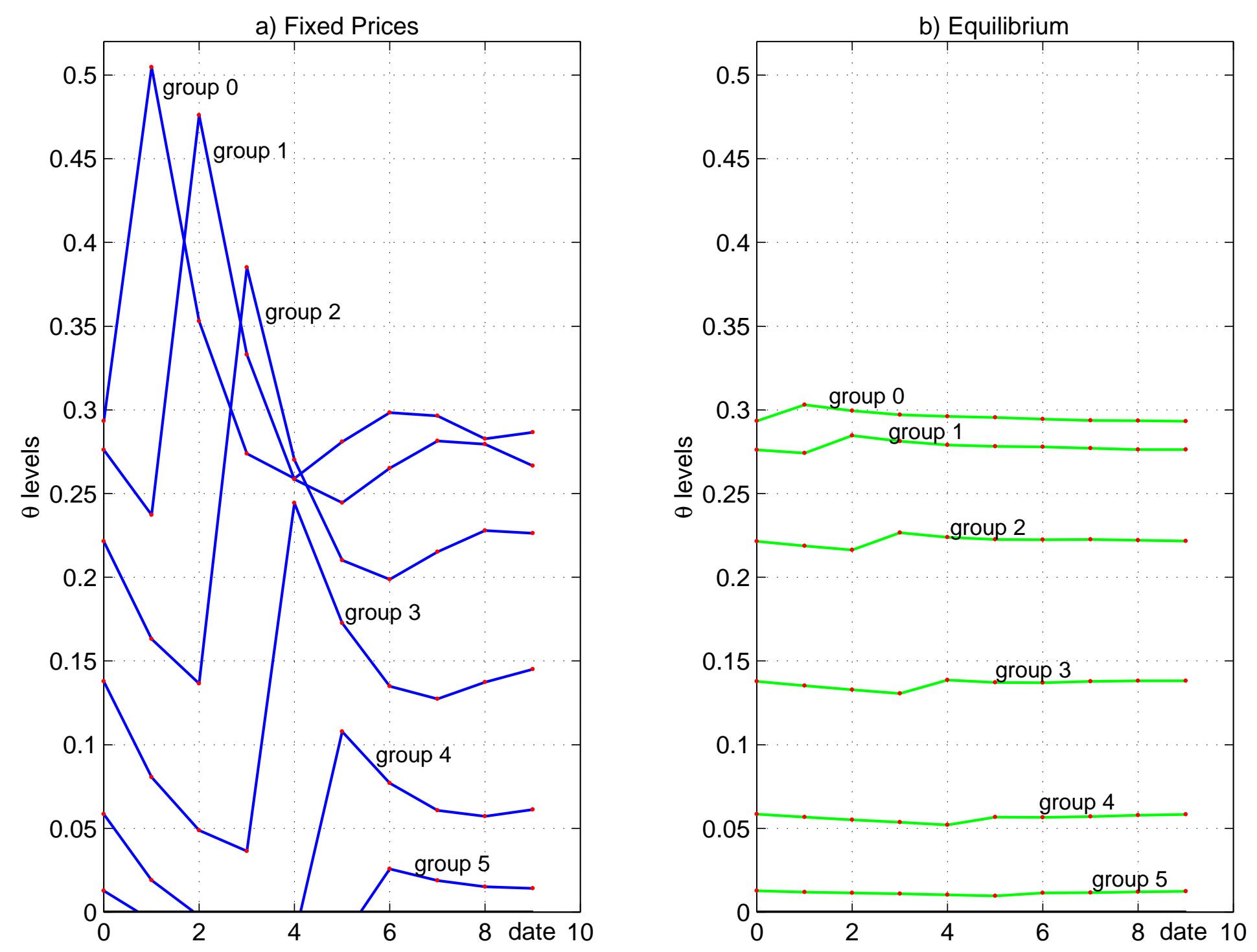

Population densities (in levels) in response to 1 percent productivity rise: (a) with prices held fixed at steady state; (b) with equilbrium price adjustment. 
Table 4: Standard deviations relative to output ${ }^{*}$

\begin{tabular}{|c||c|c|c|c|c|c|}
\hline & Output & Investment & Employment & Consumption & Wage & Interest Rate \\
\hline data & 2.16 & 2.901 & 0.959 & 0.540 & 0.287 & 0.444 \\
\hline B & 1.85 & 3.303 & 0.577 & 0.492 & 0.492 & 0.096 \\
\hline SD & 1.85 & 3.304 & 0.576 & 0.492 & 0.492 & 0.095 \\
\hline CA & 1.82 & 3.227 & 0.556 & 0.503 & 0.503 & 0.083 \\
\hline PA & 1.51 & 2.223 & 0.305 & 0.708 & 0.708 & 0.019 \\
\hline
\end{tabular}

Table 5: Contemporaneous correlations with output

\begin{tabular}{|c|c|c|c|c|c|}
\hline & Investment & Employment & Consumption & Wage & Interest Rate \\
\hline data & 0.823 & 0.903 & 0.858 & 0.263 & -0.385 \\
\hline B & 0.973 & 0.946 & 0.924 & 0.924 & 0.889 \\
\hline SD & 0.973 & 0.946 & 0.925 & 0.925 & 0.892 \\
\hline CA & 0.976 & 0.950 & 0.938 & 0.938 & 0.904 \\
\hline PA & 0.991 & 0.971 & 0.995 & 0.995 & 0.610 \\
\hline
\end{tabular}

Table 6a: First order autocorrelations

\begin{tabular}{|c|c|c|c|c|c|c|}
\hline & Output & Investment & Employment & Consumption & Wage & Interest Rate \\
\hline data & 0.463 & 0.466 & 0.440 & 0.628 & 0.325 & 0.513 \\
\hline B & 0.482 & 0.435 & 0.428 & 0.632 & 0.632 & 0.434 \\
\hline SD & 0.483 & 0.437 & 0.431 & 0.630 & 0.630 & 0.448 \\
\hline CA & 0.488 & 0.455 & 0.453 & 0.607 & 0.607 & 0.511 \\
\hline PA & 0.482 & 0.460 & 0.453 & 0.508 & 0.508 & 0.607 \\
\hline
\end{tabular}

Table 6b: Second order autocorrelations

\begin{tabular}{|c|c|c|c|c|c|c|}
\hline & Output & Investment & Employment & Consumption & Wage & Interest Rate \\
\hline data & 0.027 & -0.183 & -0.088 & 0.150 & -0.240 & 0.031 \\
\hline B & 0.121 & 0.067 & 0.060 & 0.291 & 0.291 & 0.066 \\
\hline SD & 0.121 & 0.068 & 0.060 & 0.291 & 0.291 & 0.075 \\
\hline CA & 0.126 & 0.082 & 0.077 & 0.273 & 0.273 & 0.135 \\
\hline PA & 0.121 & 0.096 & 0.087 & 0.152 & 0.152 & 0.268 \\
\hline
\end{tabular}

Column 1 reports the percent standard deviations for HP-filtered output in the data, benchmark, state-dependent adjustment, constant adjustment and partial adjustment models, respectively. (The models are briefly summarized in table 3.) Columns 2-6 are standard deviations relative to the standard deviation of output. In tables 3-6, the Hansen preference specification implies identical consumption and wage moments within each model economy. 
Table 7: Cross-correlations with output*

\begin{tabular}{|c|c|c|c|c|c|}
\hline & & $\left(\mathbf{Y}, \mathrm{X}_{-2}\right)$ & $\left(\mathrm{Y}, \mathrm{X}_{-1}\right)$ & $\left(\mathbf{Y}, \mathbf{X}_{+1}\right)$ & $\left(\mathrm{Y}, \mathrm{X}_{+2}\right)$ \\
\hline \multirow{5}{*}{ Investment } & _ _ data & 0.024 & 0.460 & 0.243 & -0.280 \\
\hline & B & 0.215 & 0.536 & 0.335 & -0.055 \\
\hline & SD & 0.215 & 0.537 & 0.337 & -0.055 \\
\hline & CA & 0.217 & 0.542 & 0.360 & -0.038 \\
\hline & PA & 0.181 & 0.520 & 0.407 & 0.026 \\
\hline \multirow{5}{*}{ Employment } & _data & -0.207 & 0.175 & 0.651 & 0.168 \\
\hline & B & 0.251 & 0.550 & 0.267 & -0.129 \\
\hline & $\ldots$ & 0.251 & 0.551 & 0.270 & -0.129 \\
\hline & $\mathrm{CA}$ & 0.254 & 0.557 & 0.297 & -0.109 \\
\hline & PA & 0.226 & 0.543 & 0.341 & -0.051 \\
\hline \multirow{5}{*}{ Consumption } & data & -0.010 & 0.508 & 0.474 & 0.127 \\
\hline & B & -0.048 & 0.335 & 0.667 & 0.397 \\
\hline & $\ldots$ & -0.048 & 0.336 & 0.665 & 0.396 \\
\hline & CA & -0.031 & 0.355 & 0.642 & 0.371 \\
\hline & PA & 0.074 & 0.447 & 0.534 & 0.194 \\
\hline \multirow{5}{*}{ Wage } & data & 0.037 & 0.085 & 0.254 & 0.208 \\
\hline & B & -0.048 & 0.335 & 0.667 & 0.397 \\
\hline & SD & -0.048 & 0.336 & 0.665 & 0.396 \\
\hline & $C A$ & -0.031 & 0.355 & 0.642 & 0.371 \\
\hline & PA & 0.074 & 0.447 & 0.534 & 0.194 \\
\hline \multirow{5}{*}{ Interest Rate } & _. data & - -0.010 & -0.314 & -0.235 & 0.026 \\
\hline & B & 0.300 & 0.562 & 0.163 & -0.235 \\
\hline & $\ldots$ SD _ & 0.300 & 0.563 & 0.179 & -0.228 \\
\hline & CA & 0.305 & 0.573 & 0.254 & -0.167 \\
\hline & PA & 0.434 & 0.544 & -0.126 & -0.486 \\
\hline
\end{tabular}

* B: Benchmark; SD: State-dependent adjustment; CA: Constant adjustment; PA: Partial adjustment. 